2019-02-22

\title{
Ten questions concerning building performance analysis
}

\author{
de Wilde, Pieter
}

http://hdl.handle.net/10026.1/13361

10.1016/j.buildenv.2019.02.019

Building and Environment

Elsevier

All content in PEARL is protected by copyright law. Author manuscripts are made available in accordance with publisher policies. Please cite only the published version using the details provided on the item record or document. In the absence of an open licence (e.g. Creative Commons), permissions for further reuse of content should be sought from the publisher or author. 


\title{
Ten questions concerning building performance analysis
}

\author{
Pieter de Wilde ${ }^{\text {a }}$ \\ ${ }^{a}$ Chair of Building Performance Analysis, School of Art, Design and Architecture, University \\ of Plymouth, Plymouth, PLA 8AA, United Kingdom
}

\begin{abstract}
Building performance analysis is an important yet surprisingly complex activity. This article explores the current understanding of the concept of building performance, and explains why its analysis is a challenging activity that mostly requires expert intervention. It addresses some of the common questions about building performance, such as: What can be learnt from other disciplines that also deal with performance? What are the benefits of applying building performance analysis in the building design process? How can building performance analysis support building operation and facility management? What is the relation between building performance analysis and the class of high performance buildings? What are the prospects of automating building performance analysis? The article concludes with some of the challenges to the development of this area of study, and provides starting points for further research in the domain of building performance analysis.
\end{abstract}

Keywords: building performance, analysis, building design, building operation, theory

\section{Introduction}

Building performance is a term often used in the Architecture, Engineering and Construction (AEC) sector, typically in association with issues like the energy efficiency of buildings, indoor environmental quality, thermal comfort or lighting. Yet the term is mostly left implicit; as already pointed out by Rahim [1]: 'technical articles of research tend to use the term "performance" but rarely define its meaning'. This is not unique to the AEC sector; the same goes for the use of 'performance' in other domains such as the automotive or computing industry. Performance in general is an important concept in today's society which is strongly focussed on efficiency and quality. However, openness of the concept of building performance and the lack of a common understanding do hinder progress in building science and industry, for instance when addressing the problem of the energy performance gap or when developing building performance contracts. Without a clear definition it is hard to see how new contributions and developments relate to previous efforts on the subject, and it is difficult to assess their contribution to knowledge. After all scientific theories are universal statements, sometimes applied to specific singular situations [2], and without a common understanding it is impossible to communicate about new statements. In industry, a contract about building performance requires an exact definition of what service is provided and paid for; without such a clear definition there is a chance of misunderstandings and conflict.

The objective of this paper is to provide an overview of the state-of-the art and current challenges in building performance analysis. It reviews the current understanding of the key concept of building performance and how this can be operationalised, as well as the principal ways in which this concept can be applied in the AEC industry. Moreover, it explores some of the issues and misconceptions that sometimes hamper work in the field, hoping to steer new researchers away from typical danger zones. The paper gives an overview of analysis 
methods, their application in design, building management and control, and their relation with high performance buildings. It concludes with some of the key challenges that require further work. In more detail, the questions asked in this paper start with inquiries into the existing knowledge on building performance analysis, providing built environment professionals and researchers with a starting point for navigating the field (Q1) as well as pointing out the inherent pitfalls in developing generic evaluation frameworks (Q2). The next questions investigate the analysis approaches and tools currently available, missing links, as well as some of the disconnects between existing approaches (Q3) and explore the reasons that make building performance analysis such a complex activity, putting down warning signs to cater for the need for flexibility and adaptability. This is followed by a brief foray into other disciplines, which explores what might be learned from these different fields and how relevant concepts may be brought into building performance analysis (Q5). The paper then turns to questions about the application of building performance analysis in the industry, honing in on building design (Q6), building operation and management (Q7), and the specific class of high performance buildings (Q8). As computing and digitisation are gaining momentum in the building sector, the paper also looks at the prospects of automation for building performance analysis (Q9). The final question (Q10) explores the main challenges and required future work in the field.

\section{Ten questions (and answers) concerning building performance analysis}

\section{Question 1: What is the current understanding of the term 'building performance'?}

As noted in the introduction, the term 'building performance' is frequently used yet seldom defined. There is a large number of articles that discuss various aspects of building performance in journals such as Building and Environment, Energy and Buildings, the Journal of Building Performance Simulation, Building Simulation: an International Journal, Building Research \& Information, Automation in Construction, Advanced Engineering Informatics, Architectural Science Review, Facilities and others. Most of these articles discuss building performance only implicitly, leaving it undefined and focussing on specific performance aspects such as energy efficiency, lighting access or thermal comfort. The same goes for most books in the architecture and building science domain. This is problematic for development of the research area. It makes it difficult for new entrants to the field to get an appreciation of the state-of-the-art in the domain, and makes it hard for established researchers to position new contributions in relation to the existent body of knowledge. However, a small set of publications gives deeper insights. A first seminal contribution is the book 'Building Performance' by Markus et al. [3]. Published as early as 1972 this already highlights the intricate interaction between buildings and humans. It positions design as a special kind of decision making, notes the need to use resources in achieving performance, and explores the role of the computer in design. Report 64 by the CIB, published in 1982 [4], discusses the use and users of the performance approach, the necessary knowledge base, determination of performance requirements, prediction of the performance of design solutions, evaluation of suitability for use, and application of the performance concept at various scales and life cycle stages. Kalay [5] explores performance-based design as an alternative paradigm to the architectural notion that 'form follows function'. Foliente [6] positions building performance in a legislative context, comparing and contrasting prescriptive and performance based building legislation. 'Assessing Building Performance' by Preiser and Vischer [7] is the seminal book on Post Occupancy Evaluation. The paper by Becker [8] hones in on performance-based building design. Augenbroe [9] contributes a deep 
discussion of the role of building performance simulation in building design. Published in 2018, 'Building Performance Analysis' [10] is the first book that attempts a comprehensive and systematic overview of the subject. For a deeper introduction to these various publications see [11].

The common understanding of building performance across these publications is that of a concept that allows to compare and contrast user needs with behaviour of a specific building, or, in other words, a concept that allows to quantify how well a building fulfils its functions. There are various models that depict this, notably the General AEC Reference Model (GARM) or 'hamburger model' by Gielingh [12], the Function-Behaviour-Structure model by Gero [13], the ASTM supply-demand model [14] and the aspect system and performance indicator model by Augenbroe [9]. A closer view notes the need to redevelop the more general 'user needs' into 'technical performance requirements', whereas 'building behaviour' is something that emerges from building systems being subject to some form of excitation or stress, which leads to observable states. See figure 1.
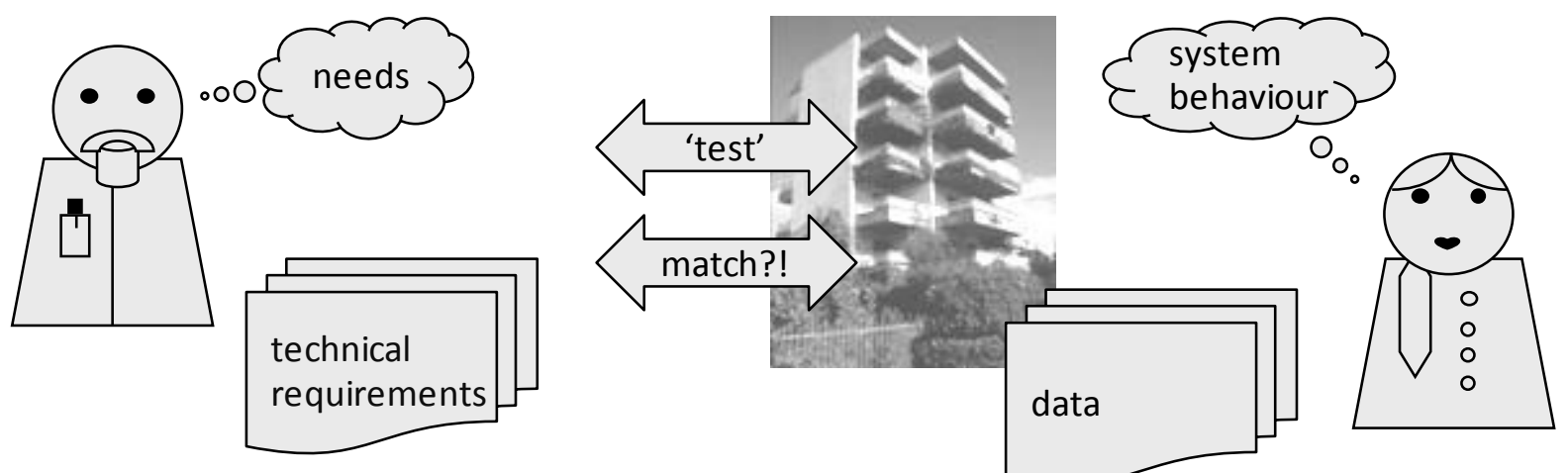

\section{Figure 1: building performance as the test of how stakeholder needs meet observed behaviour}

A wider view recognizes that building may relate to both a material object as well as the construction process. Combining this with the recent work on performative architecture in relation to building form and aesthetics $[15,16]$, this leads to a categorization where building performance can be studied from an engineering, process and aesthetic point of view [10]. Further detail on the performance of a building as a system may be added by looking across to the Systems Engineering domain, where Gilb [17] categorizes performance as consisting of quality attributes (describing how good a system fulfils functions), resource saving attributes (describing how much is needed or may be saved whilst fulfilling the function) and workload capacity attributes (describing how much as system can do). For building performance relating to the construction process, obvious performance categories relate to the iron triangle of cost, time and quality, sometimes expanded to include safety, waste reduction and customer satisfaction. Aesthetic building performance is very much a domain under development.

When looking at performance as a building attribute, it is important to acknowledge that performance is related to the building actively fulfilling a function through behaviour. Attributes such as floor area, building volume or U-value of walls may be difficult to calculate but in themselves are static building properties; they do not change by the building being subjected to excitation and do not require some sort of reaction of the building to a load in order to fulfil a function. 
Question 2: Why is there no generally accepted framework to evaluate building performance?

With all interest in building performance, and the fact that buildings are omnipresent, one may wonder why there is no generally accepted framework to evaluate building performance. There are three main causes for this situation: challenges in defining an ultimate list of the performance aspects that need to be considered, challenges in terms of the evaluation process itself, and challenges with the goals and ambitions of building stakeholders.

Performance aspects relate to the set of functions that buildings are expected to provide, such as being energy efficient, thermally comfortable, resisting wind force and internal loads, and many others. Where a function is a formal definition of something that the building is expected to do actively, and hence requires a formulation that includes an active verb (provide, resist, carry, etc), a performance aspect is the short category descriptor (energy efficiency, thermal comfort, structural load, etc). Obviously, different buildings will have different functions; some universal functions may be identified by studying key building categories like residential buildings, offices, factories, hospitals, or airports but within each of these categories there still is huge variation depending on for instance particular stakeholders, local climate conditions, local building regulations and the specific context. See figure 2 for examples of performance aspects. Some authors have attempted to provide a generic framework of building performance aspects, such as the Total Building Performance Framework [18], the ASTM Standard on Whole Building Functionality and Serviceability [19] and the Whole Building Design Guide [20]. Pre-defined categories of performance aspects deemed to be important also underlie rating schemes such as BREEAM (Building Research Establishment Environmental Assessment Method) and LEED (Leadership in Energy and Environmental Design); typically they also underpin proprietary mind maps and operation frameworks of building engineering firms such as AECOM, Arup and Perkins + Will. For a generic list of many performance aspects see www.bldg-perf.org.

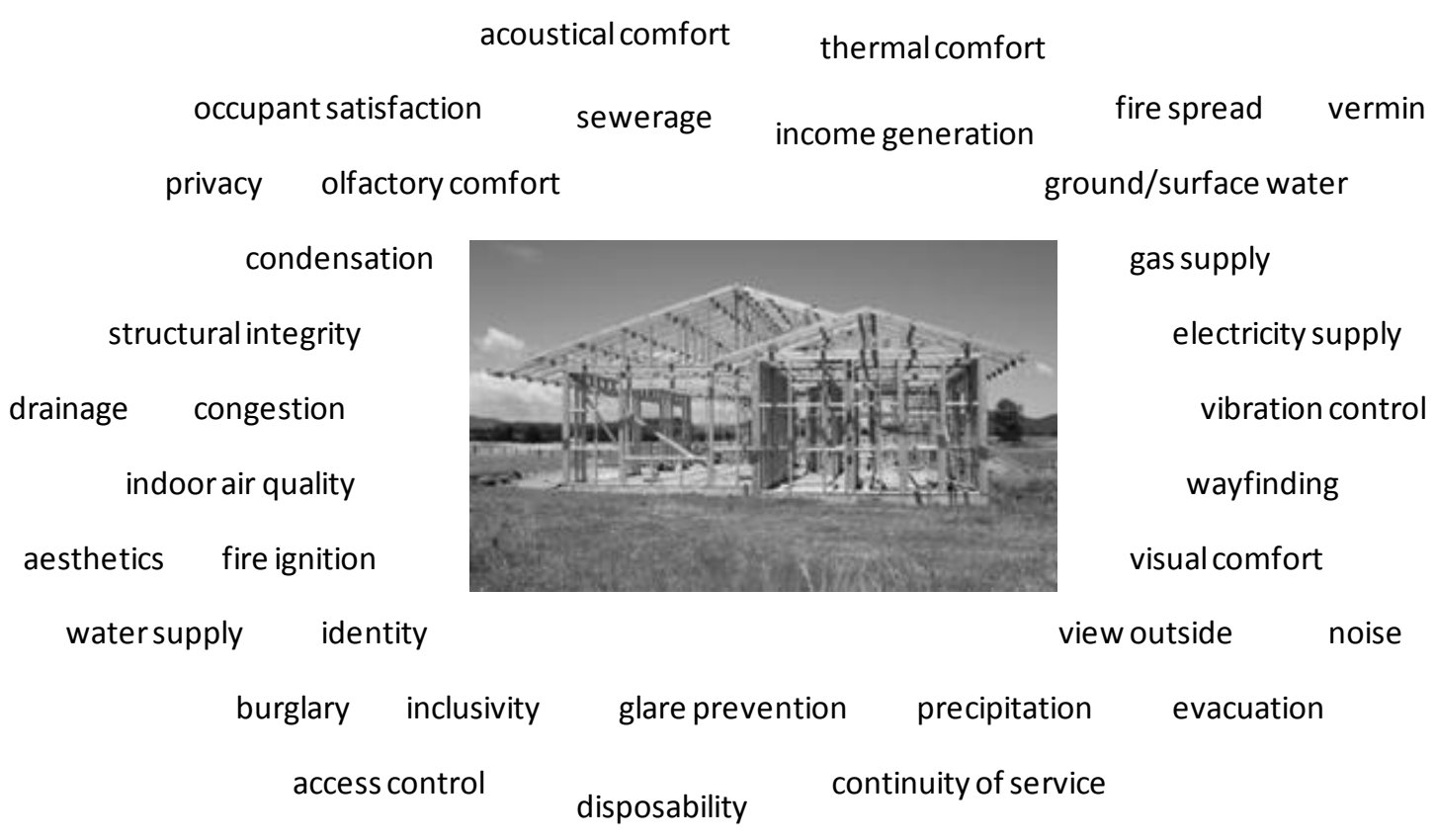

Figure 2: some of the many relevant performance aspects for buildings 
Evaluation of performance can be done in different ways, but in essence it requires the analysis of how well a building provides a certain function. This is typically done by some kind of experiment, where one observes how a building responds to some load or excitation. The experiment may take place in the physical world (measurement), in a virtual world (simulation) or in the human mind (expert judgment or stakeholder evaluation). Experiments typically study some kind of system that has an input, output and system state; each of these can be observed and, in most cases, quantified. System behaviour is typically influenced by some sort of control, and supported by relevant mechanisms [21, 22]. While there are some general guidelines for the definition of experiment [23, 24, 25], these have not yet been developed into a general format that applies to buildings. Obstacles are the complexity of buildings, the fact that the external loads and excitations are semi-controlled at best (such as outdoor weather climate, occupant behaviour, or more extreme excitations such as earthquakes or flooding), and the need to aggregate local measurements into performance measures that apply to the whole building (for instance the aggregation of temperature measurements in individual rooms to an overall measure of thermal comfort over the occupied hours of the heating season). One also needs to keep in mind that context may affect performance; for instance, in terms of energy efficiency, a building in a milder climate may have to work less hard to maintain a good indoor climate, and hence has to performs less well, than exactly the same building when exposed to a harsher climate. Some initial efforts towards the development of an universal definition of building performance experiments are Performance Test Methods [4], Performance Assessment Methods [26] and Analysis Functions [27].

Beyond this, evaluation criteria are likely to be different from project to project. Goals and targets may shift over time; see for instance the evolution of energy efficiency targets from the 1970s towards position on net Zero Energy Buildings (nZEB) or even plusEnergy Buildings from 2010 and onwards. Even where the performance aspect seems to relatively stable, such as human thermal comfort, insights and hence targets develop, as evidenced by the use of comfort temperatures, Predicted Mean Vote (PMV) and Predicted Percentage of Dissatisfied (PPD) in the well-known Fanger model, and more recent work on adaptive thermal comfort [28]. Things get even more contentious where there is an attempt to quantify building performance using one single measure, which aggregates a number of performance aspects. In this a case weighting factors need to be assigned to compute the aggregate measure. While uniform weights are embedded in most rating systems, the actual weighting typically remains an issue for debate and disagreements between stakeholders.

From this discussion it is clear that the development of a general framework for the assessment of building performance is fraught with difficulties, and should not be the aim of young researchers in the field. Instead, it is important to work with structures that are flexible and that can be adapted to the specifics of each new building case. Ensuring such flexibility and adaptability is a non-trivial challenge for future work in the field.

\section{Question 3: How complete is our building performance analysis tool set?}

There are four main approaches for the analysis of building performance: physical measurement, building performance simulation, expert judgment, and stakeholder surveys. It is interesting to note that there are few text that discuss these four approaches side-by-side. Most seminal books in the building performance domain have bias towards one specific method; for instance 'Energy Audits' [29] emphasizes physical measurement, 'Energy Simulation in Building Design' [29] obviously focuses on simulation, and 'Assessing 
Building Performance' [7] has a strong focus on stakeholder surveys; expert judgment is an underrepresented area in construction with only few pertinent publications. 'Building Performance Analysis' [10] is the first publication that tries to bring all four approaches together on a equal basis.

The tool set that is provided across all four main approaches provides analysts with a wide range of instruments, ranging from such diverse things as co-heating tests, computational fluid dynamics simulation, structured expert judgment processes, and post occupancy evaluation surveys. Yet the tool set appears to be incomplete. For some aspects, such as building heat transfer, there are tools in each category: there are monitoring approaches to measure heat flows and energy use in real buildings, thermal simulation engines allow the modelling and simulation of heat flow in buildings, expert consultants are available to judge complex situations, and there are surveys that support the evaluation of thermal conditions by the building occupants. For other aspects, this is not the case. For instance, resistance to forced entry (burglary) is typically tested in laboratory situations, with technicians employing different tools that are increasingly sophisticated to categorize resistance time and classes; yet there are no simulation tools to predict how a building design might respond to these different levels of attack. Fire testing is typically limited to façade units, and at best two or three floor heights; predicting the response of a full highrise façade is normally only tested via simulation or experts extrapolating the findings from the panel tests to a full façade. See figure 3 .

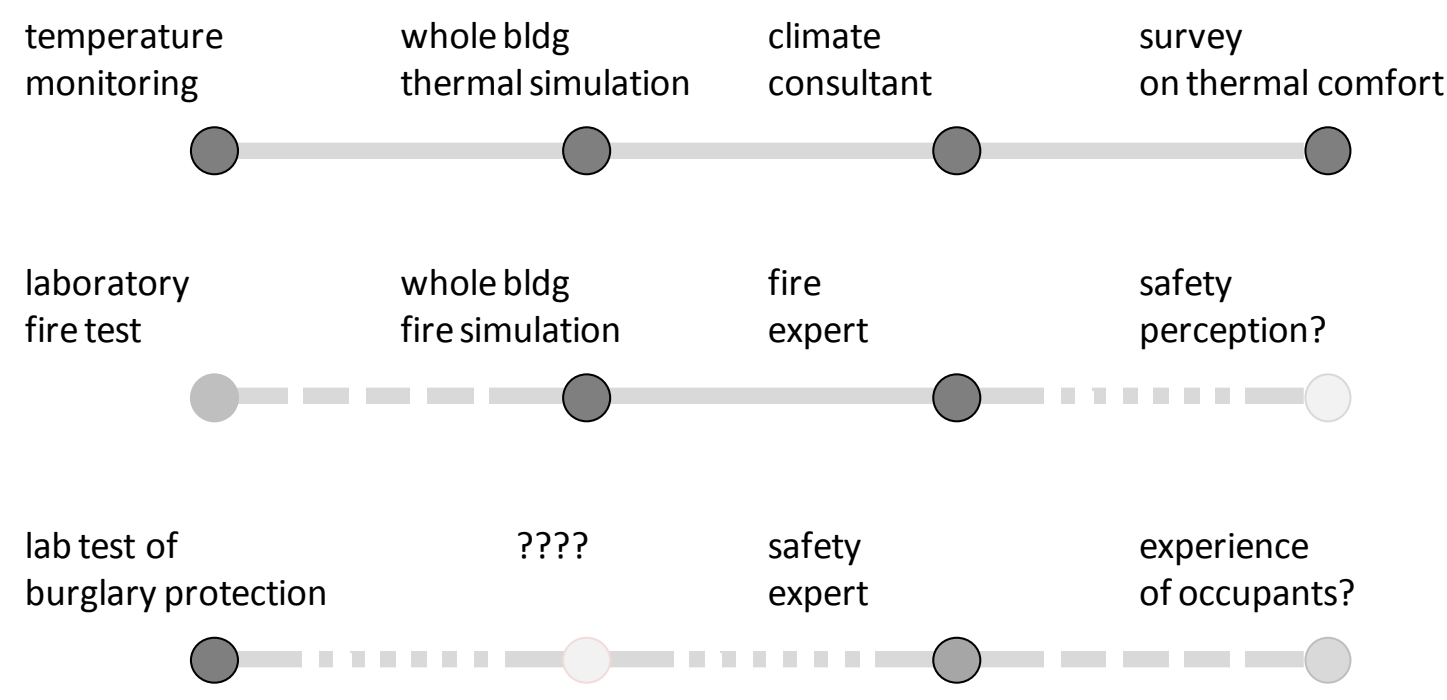

Figure 3: mapping between physical measurement, simulation, expert judgment and stakeholder evaluation for thermal, fire and burglary resistance performance

Those who explore the agreement of quantifications of building performance obtained from different categories of tools in this patchwork report that there are stark differences; for instance there is an increasing amount of publications that discuss the 'energy performance gap' between energy use as predicted by models and energy use as measured in actual buildings [31, 32, 33]. While there is little literature on the subject, it is obvious that such gaps will be present all across the tool set, and that one could also identify a 'lighting performance gap', 'acoustic performance gap', 'indoor air quality performance gap', and many others. Gaps also have a strong temporal dimension; for instance the energy performance gap as measured before system maintenance may be significantly different from 
the gap that is measured after such maintenance. Future R\&D efforts should try to complement the analysis tool set, enhancing cover across the four analysis approaches of physical measurement, building performance simulation, expert judgment, and stakeholder surveys. Where there are tools in each analysis approach, work is needed to manage the performance gap and limit it to reasonable proportions.

\section{Question 4: Why is building performance analysis such a complex activity?}

Buildings are typically bespoke, one-off products that are designed in response to the need of a specific client. Even if buildings are produced in series to the same design, as sometimes happens in the housing sector, numbers remain small and at best reach a couple of hundred units. This means that the building industry is different from other manufacturing industries such as the automotive or aerospace sector. Architectural design leads to diversity but that in turn renders almost every building a prototype, with high production cost and subject to a design process that is highly individualistic [34]. This diversity and individualism make it challenging to learn from previous processes and makes it hard to apply approaches such as the Deming or Shewart cycle. Further complexity arises from the multitude of stakeholders in buildings, which includes project developers, building occupants, financial institutions and insurers, governmental organizations, architects, engineers, contractors, facility managers, interior designers, product manufacturers, and many others; communication across this wide range of stakeholders is challenging and requires efforts to ensure common performance goals and objectives [35]. Moreover, almost all buildings are large and heavy, and therefore need to be constructed at their site, in an open environment subject to whatever weather conditions may be present. While there are continuous efforts to produce components off-site the integration of such pre-produced components still takes place locally. Construction has no single dominant technology; structures may be of precast concrete, in-situ cast concrete, metal and timber or a combination of these; the same goes for the building façade, infill, and building services. Furthermore, buildings have a long life cycle of 50 years or more, and typically undergo various deep interventions during their life cycle, such as a full façade retrofit or replacement of the heating and cooling system. This means that the object of study of building performance analysis is highly complex and variable.

As discussed under question 2, there is no single list of functions that all buildings are expected to provide, or any universally applicable list of relevant performance aspects. What is relevant for a given building is case specific, and development of the performance requirements is an important task for the building performance analyst. The analyst also needs to consider the particulars of the design, what systems are used, and what site and general climate conditions apply. Beyond that, building performance analysis requires that the analyst defines what load or excitation is applied to the building, and what building behaviour is studied. Again this is non-trivial; for instance in the domain of thermal building performance it requires the definition of weather conditions, control settings and building occupant behaviour; in an analysis of embodied energy it requires identification of production sites, required transport distances and mode of transport, and a definition of the energy mix that drives factories and transport systems.

Building performance analysis then also requires the selection of an analysis method, which relates closely to the tools that are available. For instance a lighting analysis may be driven by the decision to use a raytracing method, and the tool of choice may be the Radiance simulation engine. However, methods and tools do not map one to one; and the impact of the 
tool selected to do the analysis is likely to impact the analysis process itself by enforcing certain system views and parameters. All these factors need to be taken into account in the analysis of how the building as final product will meet its requirements, which therefore is a challenging and complex task.

All these complexities need careful consideration in all building performance analysis efforts. Projects that aim to develop a one-size-fits-all solution to ensure building performance are unlikely to be successful, and researchers wanting to make a generic contribution should define where their solutions apply, and where not.

Question 5: Can we learn from the way that other disciplines deal with performance?

Besides in building, the concept of 'performance' is used in a wide range of other application fields, such as in electronics, human resource management, the medical sector, sports and computing. Across these sit some more generic disciplines such as Systems Engineering and Process Management, which have developed worthwhile theories on systems performance. Good overviews are the Systems Engineering Handbook by INCOSE [36], the Systems Engineering Body of Knowledge [37], the seminal Systems Engineering and Analysis by Blanchard and Fabrycky [38], the handbook on Competitive Engineering by Gilb [17] or Evidence-based Productivity Improvement by Pritchard et al. [39].

Many concepts defined in the generic theories of systems engineering and process management are useful for the building industry. Amongst these are the drive to follow a holistic approach that takes all relevant performance aspects into account, an emphasis on the whole life cycle of products ('cradle to cradle'), efforts to define and check performance requirements throughout the design process, and the call for an interdisciplinary approach to ensure that all relevant aspects are appropriately addressed. Regularly, research proposals and papers emerge that suggest it is time to capitalize on the contributions in these other fields, either by straight application or a derivative course of action such as offsite or modular construction. However, application of concepts in detail requires careful examination due to the forementioned special nature of the building industry; as most buildings are unique products the principles of prototyping, feedback and improvement cycles and many other approaches do not fully map. For instance the typical building design process view such as described by the RIBA Plan of Work [40] contrasts significantly with engineering process views such as the waterfall, vee and spiral process maps [39]. Similarly, the building briefing process (named architectural programming in Northern America) as described in the seminal book by Blyth and Worthington [41] has limited overlap with more generic work in the domain of requirement engineering [42, 43].

This examination of whether or not general concepts fits with the building domain thus is an area for significant further research. Finding out what works or not in construction requires a deep insight in the building design and construction process, facility management, as well as relevant technical building domains such as building services engineering, building physics, construction management, quantity surveying and, indeed, building performance analysis as a specialism; it cannot be left to generic systems engineers and management consultants who lack insight into the particular constraints that apply in the building sector. An examples of work that discuss the applicability of system engineering principles to building design is the chapter by Augenbroe [9]; a discussion of requirement engineering in the context of building performance simulation and as enabler for intelligent computing can be found in [44]. 
Question 6: What are the benefits of applying building performance analysis in the building design process?

Building performance analysis is a key enabler for ensuring that buildings meet user needs and the associated technical requirement. It ensures that the design team sets performance targets prior to the design activity, and then checks whether the design that has emerged actually meets these targets; while leaving the process of design synthesis open and flexible. Note that design and analysis may take place in multiple iterations. Ideally, once a building is constructed performance will be monitored to check that the design analysis and operational analysis match. To some extent, building performance analysis is mandatory by law. For instance in the EU buildings are subject to the Energy Performance of Buildings Directive (EPBD) which requires that the energy use of buildings must be assessed at the design stage; a similar situation exists in the USA where the Energy Policy Act of 2005 mandates the use of ASHRAE and IECC codes. The same goes for other performance domains like lighting, sound insulation, indoor air quality and others. Note that originally, many building codes prescribed specific solutions; only in the 1990s most countries adopted performance-based codes and standards [6]. Beyond codes, clients and other building stakeholders can decide to engage with voluntary rating schemes; these are particularly successful in the domain of green and/or sustainable building. Key examples are BREEAM (Building Research Establishment Environmental Assessment Methodology), LEED (Leadership in Energy and Environmental Design), NABERS (National Australian Built Environment Rating System) or the health-based WELL rating system. Rating schemes rank buildings on the basis of building and process properties; some of these may be direct building performance attributes, such as the energy efficiency, whilst others may not, such as the mandated involvement of certain specialists in the design process. Furthermore, building performance analysis is a central element of dedicated approaches such as performance-based building design [8] or the more generic performance-based building [45, 46].

It must be noted that the underlying drivers for building performance typically are grounded in more general objectives. For example, an office building will have as primary objective to provide a productive working environment for staff working in the building; a school will have the primary objective to provide an environment conductive to learning while ensuring student health and wellbeing. What these key objectives are is defined in the specific building brief and is highly variable [41, 44]. Assessment of building performance in terms of specific performance aspects such as energy efficiency, thermal comfort and human health strongly relate to these underlying objectives, but also depend on the systems that are being selected during the design process; for instance a passive heating solution may not have ramifications for energy use but may be more critical in terms of thermal comfort.

At the fundamental level, building performance analysis during the building design process ensures that buildings meet the minimum performance thresholds as required by law; it prevents remedial actions (design changes, reconstruction, replacements, repairs) once the building starts to take shape, which typically costs significant time and money, and is damaging to the reputation of those involved. Demonstrating performance that goes beyond legal requirements can be a marketing and reputational instrument, which is beneficial to the building owner and occupier; it demonstrates ambition and can be used to show corporate social responsibility. Building performance analysis is crucial for the design of 'high performance buildings' as the group of buildings that aspires to be 'best of class', and which requires evidence to demonstrate that they belong in this category.

There is a significant body of literature that discusses the process of designing for building performance, such as the deep book chapter by Augenbroe [9] and the wide 
overview in the book of Mumovic and Santamouris [47]. Yet this is a challenging area of study, where there is a limited evidence base; see for instance the work by Bleil de Souza [48, 49] for good insights. In general, it is important to note that design theory can roughly be classified in three categories: (1) design as a technical decision making process, which can be rationalized; (2) design as a complex activity that is partly intuitive and creative, partly rational, and that at best can be observed and studied, but always requires flexibility; and (3) design as an art that requires the input of experts and refutes prescription; for a further discussion see [50]. Researchers in the area of performance-based building design should be critical about generic calls for efforts in early/conceptual design, early design tools and integral/integrated design, and investigate the deep specifics of any such proposals.

\section{Question 7: How can the use of building performance analysis support building operation and management?}

Once a building is constructed and operational, building performance analysis yields data that can be used for various purposes. The data can be used to compare actual performance with design intentions; it can be used as input for the control of building systems; and it can also be used to compare the performance of a building over time, and with that of a group of peers. All of these are useful in detecting faults and anomalies, and in ensuring that buildings perform as expected. A generic term that covers many of these different uses is building performance tracking [51]. This is an area of significant research activity, where building performance analysis meets the concepts of Artificial Intelligence (AI), Machine Learning, and Big Data analysis.

The operation of building systems is typically controlled by a building management system (BMS), which relies on a range of sensors to capture the status of the building and systems. Additional performance data may be harvested by dedicated measurement and monitoring activities [52]. Often measurement is done remotely and automated; a key term in this context is automated meter reading (AMR).

Two concepts that relate to the use of building performance analysis data in building management are monitoring and targeting $(M \& T)$ and measurement and verification $(M \& V)$. M\&T measures building performance in order to identify exceptions which then can be acted upon, thus improving performance. $\mathrm{M} \& \mathrm{~V}$ is closely related but typically takes place in the context of a performance contract; the verification part explores whether agreed performance is indeed achieved. A key standard for both M\&V and M\&T processes is the IPMVP or International Performance Measurement and Verification Protocol [53].

Another concept relevant in the context of building operation and management is fault detection and diagnosis (FDD). Like the other approaches FDD analyses building performance to identify when performance is outside expected bounds in order to pinpoint faults; however FDD also attempts to indicate what exactly it is that causes the anomaly. A good overview of FDD in the building services is provided by Katipamula and Brambley [54, 55]. FDD is a challenging area, as there may be different reasons for abnormal performance readings and identifying root causes is non-trivial in the complexity of a building. For machine learning approaches to work properly, significant efforts are required to prepare clean training data for the computational processes; separating signals of interest ('building vitals') from general signal noise is often complex and underestimated and a field where more research and development efforts are needed. 
Question 8: How does building performance analysis relate to the concept of high performance buildings?

A category of buildings that is inherently linked to the concept of building performance is that of high performance buildings; by their very name these buildings aspire to be 'best of class'. In individual building (design) project the term high performance can be used to indicate an ambition level. The more general notion of high performance buildings as a distinct class of buildings stems from North America and the publication of guidelines by the city of New York in 1999 [56], with further detail added by the National Institute of Building Science [57, 58] and ASHRAE [59]. However, other authors use the term much more loosely, as exemplified by an EU report that equates high performance buildings to eco buildings, low energy houses, passiv houses, green buildings and similar [60].

While there is no common definition of what exactly constitutes a high performance building, a couple of comments can be made. First of all, since there are many performance aspects, there is no generic one-size-fits-all list of performance aspects that need to be addressed, in spite of some suggestions in that direction $[57,58]$. However, one might expect that any building that is labelled as 'high performance' to specify the performance aspects that have been considered. Secondly, to qualify as 'high performance' such a building should have been the subject of some sort of quantitative analysis. This analysis must demonstrate how the performance of the building relates to the performance of its peers, and indicate that the building indeed is in the highest ranking group.

\section{Question 9: Can we automate building performance analysis?}

Automation requires a process that has inherent process logic and which is regularly repeated. An example is the working of a thermostat, which automatically shuts down the hot water supply once a certain room temperature is achieved, replacing the need to manually shut down the heating system. Automation applies to some parts of building performance analysis, but not to others. As argued before most buildings are unique, and defining what performance aspects are relevant, what performance targets are applied, and how performance is to be quantified will require manual intervention. This part of any analysis is a knowledge-intensive activity that requires expertise of those involved; defining the question that needs to be solved by intelligent computing is one of the most challenging aspects. To move forward one needs to map existing processes in significant detail, and to indentify the recurring tasks; this is the case independent of whether the analysis process employs physical measurement, computational analysis/simulation, expert judgment or stakeholder evaluation. Process mapping and requirement engineering may help to do part of this work of capturing the recurrent tasks and identifying where automation may be beneficial [44].

In terms of ICT, clearly defined tasks such as importing building geometry from a building information model into a energy simulation input file are recurrent processes and do benefit from automation [62]; and so the paradigm of building information modelling or BIM $[62,63]$ is also changing the world of building performance analysis. There are various approaches, such as direct mappings from BIM to native simulation models as well as the use of the intermediate gbXML format. Where analysis tasks are well-defined, for instance in the case of normative calculations that follow a standard analysis may follow automatically, as demonstrated by compliance checking as available on various platforms. However, more complex and bespoke analysis efforts remain more problematic, as demonstrated by a range of efforts [27, 30]; the experience of 20 years of work on the issue shows that fully autonomous building performance analysis faces serious challenges. 
Question 10: What are the main challenges related to building performance analysis that most urgently need to be addressed?

Building performance analysis is an essential tool to address some of the pressing challenges that face the built environment, such as environmental (energy use, greenhouse gas emissions, material use, waste), economic and productivity, or human health, wellbeing and safety issues. Performance analysis quantifies how well a certain building or design meets such challenges, supporting design and directing interventions in the existing building stock. Yet there is a range of issues that needs further work:

- Terminology on building performance is diverse and often lacking, and needs further development.

- Concepts from other disciplines such as systems engineering, process management and manufacturing need to be critically reviewed for applicability in the architecture, engineering and construction domain.

- Performance quantification approaches (measurement, simulation, expert judgment and stakeholder evaluation) live in four different worlds, and need better alignment. Specific attention is needed for a wide range of 'performance gaps' that may be present across all four methods and a host of performance aspects, and across different points in time.

- Building performance analysis software needs a deep review to better connect with design and facility management requirements, while capitalizing on the developments in BIM and computing in general such as cloud computing.

- Automated Meter Reading is creating big data on building performance; approaches to analyze this data and distil actionable information need to be developed.

- Education in the area of building performance analysis needs development, to ensure the industry gets access to professionals who have a holistic view and can integrate along different performance aspects and analysis methods.

- Design theory for the development of well-performing and high performance buildings needs development, building on the first ideas [16] in the area of building performativity.

- The process and aesthetic dimensions of building performance analysis require further work. On the process side, the emphasis is mainly on preventing defects or time and cost overruns, but a wider scope should be adapted. The aesthetic view is only just emerging and needs significant further development.

Overall the body of knowledge on building performance analysis is still dispersed over many disjoint contributions. There are calls for an overarching framework, for instance as championed by Clarke [64, 65] for the specific domain of building performance simulation. A first attempt to bring the existent body of knowledge together in one source is the book 'Building Performance Analysis' [10]; the final chapter of this work presents an emergent theory that lists a number of observations, explanations, principles and hypothesis that offer a starting point for further research and development.

\section{Discussion and conclusion}

Building performance analysis is a key enabler for the design, construction and operation of buildings that meet the expectations of a wide range of stakeholders. In an engineering perspective, the concept compares and contrasts user needs, specified as technical performance requirements, with the observed and quantified behaviour of a building 
subjected to some kind of excitation or stress. Different views may also study the performance of the building construction process, and aesthetic performance.

Buildings are highly complex and bespoke products, which poses special constraints for the analysis process. As stakeholders, location, technology used, building functions and many other issues vary from project to project, analysis efforts need to be tailored to the specific context, limiting the prospects of one-size-fits-all approaches and mostly requiring human expert intervention.

There are many contributions on the subject of building performance, with a conservative estimate suggesting at least 60,000 papers spread out over a range of journals. This makes it difficult for novices to enter the field, gain an appreciation of the existing body of knowledge, and then to make a clear contribution towards the state-of-the-art. Reading of key references such as those cited in this paper is essential for new entrants and needed to ensure that the field of building performance analysis makes progress.

\section{References}

[1] A. Rahim, Performativity: beyond efficiency and optimization in architecture, in: B. Kolarevic and A. Malkawi (Eds.), Performative Architecture: Beyond Instrumentality, Spon Press, New York, 2005, pp. 177-192.

[2] K. Popper, The Logic of Scientific Discovery, Routledge, London, 1992, pp. 37-40.

[3] T. Markus, P. Whyman, J. Morgan, D. Whitton, T. Maver, D. Canter, J. Fleming, Building Performance, Applied Science Publishers, London, 1972.

[4] Working Commission W60, CIB Report 64: Working with the Performance Approach to Building, CIB, Rotterdam, 1982.

[5] Y. Kalay, Performance-based design, Autom. Constr. 8 (1999) 395-409.

[6] C. Foliente, Developments in performance-based building codes and standards, For. Prod. J., 50 (2000) 12-21.

[7] W. Preiser and J. Vischer, Assessing Building Performance, Elsevier, Oxford, 2005.

[8] R. Becker, Fundamentals of performance-based building design, Build. Simul. 1 (2008) 356-371.

[9] G. Augenbroe, The role of simulation in performance based building, in: J. Hensen and R. Lamberts (Eds.), Building Performance Simulation for Design and Operation, Spon Press, Abingdon, 2011, pp. 15-36.

[10] P. de Wilde, Building Performance Analysis, Wiley, Oxford, 2018.

[11] P. de Wilde, The concept of building performance in building performance simulation: a critical review, 15 ${ }^{\text {th }}$ IBPSA Conf. San Francisco, USA, 2017.

[12] W. Gielingh, Improving the Performance of Construction by the Acquisition, Organization and Use of Knowledge, PhD thesis, TU Delft, the Netherlands, 2005.

[13] J. Gero, Design prototypes: a knowledge representation schema for design, AI Magazine, 11 (1990) 26-36.

[14] F. Szigeti and G. Davis, Using the ASTM/ANSI standards for whole building functionality and serviceability for major asset and portfolio decisions, CIB W070 Glob.Symp., Glasgow, UK, 2002, 507-521.

[15] B. Kolarevic, B., A. Malkawi (Eds.), Performative Architecture: Beyond Instrumentality, Spon Press, New York, 2005.

[16] M. Hensel, Performance-oriented Architecture: Rethinking Architectural Design and the Built Environment, Wiley, Chichester, 2013.

[17] T. Gilb, Competitive Engineering: a Handbook for Systems Engineering, Requirements Engineering, and Software Engineering Using Planguage, ButterworthHeinemann, Oxford, 2005. 
[18] V. Harkopf, V. Loftness and P. Mill, The concept of total building performance and building diagnostics, in: G. Davis (Ed), Building performance: function, preservation and rehabilitation, ASTM, Philadelphia, 1986.

[19] F. Szigeti, G. Davis and D. Hammond, Introducing the ASTM facilities evaluation method, in: W. Preiser and J. Vischer (Eds), Assessing Building Performance, Elsevier, Oxford, 2005.

[20] National Institute of Building Science, Whole Building Design Guide. www.wbdg.org, 2018 (accessed 12 November 2018).

[21] B. Zeigler, H. Praehofer and T. Kim, Theory of modeling and simulation,Academic Press, London/San Diego, 2000.

[22] A. Malkawi and G. Augenbroe, Advanced building simulation, Spon Press, New York, 2003.

[23] G. Weinberg, A introduction to general systems thinking, Dorset House Publishing, New York, 1975.

[24] D. Montgomery, Design and analysis of experiments, Wiley, Hoboken, 2013.

[25] C. Wu and M. Hamada, Experiments - planning, analysis, and parameter design optimization, Wiley, Chichester, 2002.

[26] IEA, Annex 21: Calculation of energy and environmental performance of buildings. Subtask B: appropriate use of programs, BRE, Watford, 1994.

[27] G. Augenbroe, P. de Wilde, H. Moon and A. Malkawi, An interoperability workbench for design analysis integration, Energ. Build. 36 (2004) 737-748.

[28] R. de Dear, T. Akimoto, E. Arens, G. Brager, C. Candido, K. Cheong, B. Li, N. Nishihara, S. Sekhar, S. Tanabe, J. Toftum, H. Zhang and Y. Zhu, Progress in thermal comfort research over the last twenty years, Indoor Air 23 (2013) 442-461.

[29] T. Al-Shemmeri, Energy Audits, Wiley-Blackwell, Chichester, 2011.

[30] J. Clarke, Energy Simulation in Building Design, second ed., ButterworthHeinemann, Oxford, 2001.

[31] C. Menezes, A. Cripps, D. Bouchlaghem and R. Buswell, R., Predicted vs. actual energy performance of non-domestic buildings: Using post-occupancy evaluation data to reduce the performance gap, Appl. Energ. 97 (2012) 355-364.

[32] C. Turner and M. Frankel, Energy performance of LEED for new construction buildings, White Salmon (WA): New Buildings Institute, 2008.

[33] P. de Wilde, The gap between predicted and measured energy performance of buildings: a framework for investigation, Autom. Constr. 41 (2014) 40-49.

[34] G. Foliente, Incentives, barriers and PBB implementation, in: R. Becker (Ed), Performance Based Building international state of the art, CIB, Rotterdam, 2005.

[35] M. Frankel, J. Edelson and R. Colker, Getting to outcome-based building performance, New Buildings Institute, Vancouver WA, 2015.

[36] INCOSE, Systems engineering handbook. Wiley, San Diego, 2015.

[37] The guide to the systems engineering body of knowledge, v.1.3. Trustees of the Stevens Institute of Technology, Hoboken, 2014.

[38] B. Blanchard and W. Fabrycky, Systems engineering and analysis, fifth ed., Prentice Hall, Upper Saddle River, 2011.

[39] R. Pritchard, S. Weaver and E. Ashwood, Evidence-based productivity improvement, Routledge, New York/London, 2012.

[40] RIBA Plan of Work. Royal Institute of British Architects, Bristol, 2013.

[41] A. Blyth and J. Worthington, Managing the brief for better design, second ed., Routledge, Abingdon, 2010.

[42] E. Hull, K. Jackson and J. Dick, Requirements engineering, London, Springer, 2011. 
[43] S. Robertson and J. Robertson, Mastering the requirements process, third ed., Addison-Wesley, Upper Saddle River, 2013.

[44] P. de Wilde, Intelligent computing for building performance analysis, in I. Smith and B. Dorner (Eds.), LNCS: Advanced Computing Strategies for Engineering, Cham, Springer, 2018.

[45] W. Bakens, G. Foliente and M. Jasuja, Engaging stakeholders in peformance-based building: lessons from the Performance-Based Building (PeBBu) network, Build. Res. Inf. 33 (2005) 149-158.

[46] M. Jasuja, PeBBu Final Report, CIB, Rotterdam, 2005.

[47] D. Mumovic and M. Santamouris (Eds.), A handbook of sustainable building design and engineering, second ed.. Routledge, Abingdon, 2019.

[48] C. Bleil de Souza, Contrasting paradigms of design thinking: the building thermal simulation tool user vs the building designer, Autom. Const. 22 (2012) 112-122.

[49] C. Bleil de Souza, Studies into the use of building thermal physics to inform design decision making, Autom. Cons. 30 (2013) 81-93.

[50] P. de Wilde and C. Bleil de Souza, Performative design strategies: the synthesis process of a woven complexity, in: M. Kanaani (Ed). The Routledge companion to paradigms of performativity in design and architecture, Routledge, 2019 (in press).

[51] California Commissioning Collaborative, The building performance tracking handbook, 2011.

[52] K. Gillespie, P. Haves, R. Hitchcock, J. Deringer and K. Kinney, A specification guide for performance monitoring systems, LBNL, Berkeley, 2007.

[53] Efficiency Valuation Organization, International Performance Measurement and Verification Protocol: core concepts, EVO, Washington, 2014.

[54] S. Katipamula and M. Brambley, Methods for fault detection, diagnostics and prognostics for building systems: a review, part I. HVAC\&R Res. 11 (2005) 3-25.

[55] S. Katipamula and M. Brambley, Methods for fault detection, diagnostics and prognostics for building systems: a review, part II. HVAC\&R Res. 11 (2005) 169187.

[56] City of New York, Department of Design and Construction, High Performance Building Guidelines, New York, 1999.

[57] National Institute of Building Science, Assessment to the US Congress and US Department of Energy on high performance buildings, Washington, 2008.

[58] National Institute of Building Science, Data needs for achieving high-performance buildings, Washington, 2011.

[59] D. Grumman and A. Hinge, What makes a building high performing. High Perf. Build. (2012) 46-54.

[60] H. Erhorn and H. Erhorn-Kluttig, Terms and definitions for high performance buildings, Concerted Action: Energy Performance of Buildings, Brussels, 2011.

[61] C. van Treeck, R. Wimmer and T. Maile, BIM for energy analysis, in: A. Borrmann, M. König, C. Koch and J. Beetz (Eds.), Building Information Modelling, Springer, Cham, 2018, pp. 337-347.

[62] C. Eastman, P. Teicholz, R. Sacks and K. Liston, BIM Handbook: a guide to bulding information modelling, second ed., Wiley, Hoboken, 2011.

[63] A. Borrmann, M. König, C. Koch and J. Beetz (Eds.), Building Information Modelling: technology foundations and industry practice, Springer, Cham, 2018.

[64] J. Clarke, A vision for building performance simulation: a position paper prepared on behalf of the IBPSA Board, J. Build. Perf. Sim. 8 (2015) 39-43.

[65] J. Clarke and J. Hensen, Integrated building performance simulation: progress, prospects and requirements, Build. Environ. 91 (2015) 294-306. 